\title{
Species identities impact the responses of intensity and importance of competition to the change of soil nutrition condition
}

\author{
Nianxi Zhao ${ }^{1}$, Yujuan $\mathrm{Xu}^{1}$, Liping Chen ${ }^{1}$, Man Jiang ${ }^{1}, \mathrm{Ke} \mathrm{Dong}^{1}$, Jinlong Wang ${ }^{2}$, and \\ Yubao Gao ${ }^{1}$ \\ ${ }^{1}$ Nankai University College of Life Sciences \\ ${ }^{2}$ Affiliation not available
}

May 14, 2020

\begin{abstract}
Aims How plant-plant interactions vary with the changes of biotic and abiotic factors has debated for a long time among ecologists. The aim of this study was to explore how different neighbors influenced the responses of the intensity and importance of competition on Stipa grandis and S. krylovii to the change of soil nutrition condition. Methods The seedlings of the target species, S. grandis and S. krylovii, were grow alone and in two-species mixtures with different neighbors under two soil nutrition treatments. For each target species, we measured the biomass, root: shoot ratio, intensity and importance of competition and nutrition-addition effect. Important Findings We founded that the competition responses were mediated by the identities of neighbors and target species. (1) When in mixture with Leymus chinensis, both intensity and importance of competition negatively increased with the increase of soil nutrition. The competition importance was significantly negative on $S$. grandis under both soil nutrition treatments and on S. krylovii under the high soil nutrition treatment, supporting Grime's theory.

(2) When in S. grandis - S. krylovii mixture system, the competition inhibition decreased while competition importance showed no significant effects on both target species with the increase of soil nutrition, indicating competitive reduction. (3) When in mixture with Agropyron cristatum, the competition intensity significantly influenced by the interaction between target species and soil nutrition, suggesting competitive change along the soil nutrition gradient. The competition importance was significantly negative on $S$. grandis under the low soil nutrition treatment and on S. krylovii under the high soil nutrition treatment. Ultimately, our results demonstrate that the identities of both target and neighbor species influenced the responses of intensity and importance of competition to the change of soil nutrition condition. Several mechanisms potentially contributed to these different competition effects on different target species.
\end{abstract}

\section{Introduction}

It is clear that environmental changes could alter plant community composition and diversity, and competition (plant - plant interaction) is often considered as one of the main drivers of the consequence of environmental changes (Grime, 1979; Tilman, 1982). Therefore, plant ecologists have been investing tremendous efforts in interpreting and predicting how the intensity (amount of inhibition or facilitation in the target's performance as a consequence of a neighbor's presence) and importance (the impact of a neighbor on the target expresses as a proportion of the total environmental impact on the target) of competition varies along the environmental gradients especially soil nutrition gradient, and have concluded three theory models with empirical evidences (Bertness et al. 1994; Brooker et al. 2005; Gaucherand et al. 2006; Grime, 1979; Laurent et al. 2017; Tilman, 1982). First, it is assumed that competition inhibition would decrease from benign (fertile) habitats to harsh (unfertile) habitats, which is called "stress gradient hypothesis" (Bertness and Callaway 1994; Grime, 1979). Second, it predicts that total competition is equally important throughout 
soil resource gradients, and belowground competition is most intense for soil water and/or nutrition in unfertile sites and aboveground competition is most intense for light and space (aerial competition) in fertile sites, which is called Tilman's theory (Tilman, 1987). Third, it argues that competition importance increases with the increase of resource availability and it is higher in fertile environments, which is called Grimes's theory (Grime, 1977).

Although plenty of experiments have successfully supported these models under different soil resource conditions, there is a growing number of experiments that have emphasized the importance of species identities (both target and neighbor) in influencing competition for resources and consequently influencing the community composition and structure (Read, 2016; Suding et al. 2004; Yelenik et al. 2017). The responses of a single target species varying based on the identities of neighbors have been found in several studies (Kong et al. 2018; Stoll et al. 2000). For example, Keddy et al. (2002) found that the response of a single target species to competition was equally sensitive under two different environmental conditions but varied with the identities of 63 experimental competitors. These experiments have also shown that the effect of neighbor identity to competitive intensity may even surpass that of environmental differences. Although there were not consistent conclusions, two components of species, the effects of neighbors on resource availability (the growth potential) and the ability of individuals to tolerate these effects, were usually considered when researchers tried to understand how species identities influenced the outcomes of plant-plant interaction (Goldberg, 1996; Suding et al. 2004). In addition, ecologists found that the co-occurring species may compete or facilitate one another by modifying the microbial environment to change nutrition availability (Brooker et al.2008). Several studies have found out that a species could influence the outcomes of plantplant interaction by immediate effect when another species co-occurred with it, legacy effect or plant-soil feedback when another species grew in the soil that it has been conditioned (Zhao et al. 2018).

Suding and Goldberg (2001) addressed the processes responsible for the patterns of species composition change after the environmental changes, and suggested that both competitive reduction and competitive change were two alternative hypotheses to explain the relative competitive abilities of different target species affected by different neighbor species in changing environmental conditions. The competitive reduction hypothesis predicts no shift of competitive hierarchies of the target species, suggesting environmental changes may modify species associations simply; while the competitive change hypothesis predicts competitive hierarchy of target species may shift with the change of environmental conditions, thus influencing the species composition, not just the intensity of competition (Suding et al. 2001). Therefore, considering the species identities is very important for understanding the community processes and intrinsic mechanisms in the context of global changes which have altered the soil resource conditions and community composition and structure dramatically.

Arid and semi-arid grasslands are very sensitive to the environmental changes. In this region, nature ecosystems are being degrading to more stress conditions because of over-grazing and drought (Huang et al. 2019; Ren et al. 2018). Simultaneously, the observed acceleration in N cycle caused by fossil fuel combustion, fertilizer use and legume shrub invading into grassland substantially have contributed to soil nutrition (Chen et al. 2019; Zhou et al. 2019). The different responses (growth potential or tolerance) of different species to such changes would influence the outcome of plant-plant interaction, alter plant community composition and diversity. Similar to the worldwide terrestrial communities, the semi-arid steppe of China is suffering from global changes (Li et al. 2012). In this region, Stipa grandis community is the most normal, stable and representative community, and it is very sensitive to environmental changes; and compared with $S$. grandis ,S. krylovii occupies dryer and more infertile habitats. The previous experiments demonstrated that the lower tolerance of $S$. grandis to drought, disturbance and infertile soil condition might be the reason for the replacement of $S$. grandis by $S$. krylovii (Chen et al. 2013). Recent study showed that soil conditioned by $S$. grandis with high N treatment could increase $S$. krylovii 's competition superiority and N-addition effect in a low-density controlled experiment (Zhao et al. 2018). Therefore, exploring how the identities of neighbors influenced the competition hierarchies of $S$. grandis and S. krylovii under different soil nutrition conditions is very important for us to understand the mechanisms of community dynamics and predict community processes. 
In this study, we conducted a microcosm experiment to explore how soil nutrition condition, neighbor species influenced the intensity and importance of target species (S. grandis and S. krylovii), how plantation condition, species identity influenced nutrition-addition effect, and how the variation of the competitive hierarchy altered with the change of soil nutrition when the target species were grown with different neighbors. Especially, we conjectured that the factor of soil nutrition condition might not be the main driver that influenced the intensity and importance of competition on S. grandis and S. krylovii. What's more, we hypothesized that $S$. krylovii would show a higher competitive hierarchy than $S$. grandis in the low fertility condition. Such results would be very important for us to understand and predict the community dynamic in the semi-arid steppe of China when facing environmental changes.

\section{Material and methods}

\section{Study materials}

In this study, four abundant species in the Inner Mongolia Steppe were used. S. grandis and S. krylovii were used as the target species and as neighbor for each other. Both S. grandis andS. krylovii, two perennial tussock grasses, are the two of the most widely distributed grasses and dominate the landscape of the vast semi-arid area of the Inner Mongolia steppe, China. S. grandiswith a canopy height over $100 \mathrm{~cm}$ is a superior competitor for light and has lower tolerance to unfertile condition than $S$. krylovii, thus $S$. grandis occupies relatively moist and fertile typical grassland while $S$. krylovii occupies dry and infertile habitats (Chen et al. , 2013). The growth potential of $S$. kryloviishould be comparable to that of $S$. grandis because the communities under seriously disturbance such as grazing, $S$. krylovii would co-dominate the communities with $S$. grandis or even dominate the communities by replacing the dominance of $S$. grandis ( $\mathrm{Lu}$ and Wu 1996).

Leymus chinensis and Agropyron cristatum were used as neighbor species in this study. L. chinensis can be a dominant species in the meadow grasslands, and usually co-dominates the typical communities with $S$. grandis or S. krylovii in the Inner Mongolia steppe, which indicated that the growth potential of $L$. chinensis may be one of the highest in the Inner Mongolia Steppe and the tolerance to low nutrition of $L$. chinensis should be comparable to that of S. krylovii (Zhu, 2004). A. cristatum is a companion species in non-degraded $S$. grandiscommunity and a subdominant species in moderate-grazed $S$. grandisor $S$. krylovii communities, suggesting that the growth potential and the tolerance to low nutrition of A. cristatum are between those of $S$. grandis and S. krylovii (Xu et al. 2015).

In a $S$. grandis - S. krylovii community in the middle of Inner Mongolia Steppe $\left(44^{\circ} 15^{\prime} \mathrm{N}, 116^{\circ} 23^{\prime} \mathrm{E}, 1132\right.$ $\mathrm{m}$ altitude), the seeds of the four species were obtained and $5^{\sim} 20 \mathrm{~cm}$ soil was collected and homogenized for the microcosm experiment. The soil was a Calcic luvisol (FAO-UNESCO), with the $\mathrm{pH}$ of 7.35. The soil organic matter, availability of $\mathrm{N}$ and $\mathrm{P}$ were $15.6 \mathrm{mg} / \mathrm{g}, 0.17 \mathrm{mg} / \mathrm{kg}, 4.72 \mathrm{mg} / \mathrm{kg}$, respectively.

\section{Experimental design}

We conducted a microcosm experiment with three-factor factorial design. The first factor was target species, including $S$. grandis and S. krylovii. The second factor was soil nutrition condition with low nutrition treatment (no nutrition addition) and high nutrition treatment (adding slow-release inorganic fertilizer twice). The third factor was plantation condition, with S. grandis and S. kryloviigrown alone and in two-species mixtures (each in mixture with L. chinensis and A. cristatum, respectively, and in S. grandis - S. krylovii mixture system). The target species grown alone was used for calculating the intensity and importance of competition. Therefore, the factor of neighbor species was viewed as the third factor when we analyzed the effect on the intensity and importance of competition in order to avoid ambiguity with "plantation condition".

The seeds of each species, S. grandis, S. krylovii ,L. chinensis and A. cristatum, germinated in sterile sand, then seedlings of similar sizes were transplanted into the pots on July 4, 2011. Each pot with 20-cm depth and $10-\mathrm{cm}$ diameter was filled with $1.5-\mathrm{kg}$ soil. The high nutrition treatment was added $5 \mathrm{~g} / \mathrm{pot}$ slowrelease inorganic fertilizer $\left(15 \% \mathrm{~N}, 9 \% \mathrm{P}_{2} \mathrm{O}_{5}, 9 \% \mathrm{~K}_{2} \mathrm{O}\right)$ at the beginning and the middle of the experiment. 
For the treatment of target species grown alone, only one seedling were planted in each microcosm, and for the treatment of two-species mixture, one seedling per species was planted with the distance of $2 \mathrm{~cm}$. Each treatment was replicated six times, totaling 168 microcosms used in this experiment. The location of each microcosm was randomly changed every week to avoid position effect. The experiment was carried out in the experimental field at Nankai University, and lasted 19 weeks. During the experiment, weeds in the microcosms were removed regularly, and shading, water stress, and light stress were avoided. At the end of the experiment, the individuals in each microcosm were obtained by species, dried to a constant mass and weighed. The root: shoot ratio which is a common response to the competition for soil nutrient and light was calculated (Reynolds et al. 1993; Robinson et al, 2010).

\section{Measurements of the intensity and importance of competition}

To quantify the competition intensity, we calculated the target response to competition for each target species using the natural-log transformed response ratio (ln RR) (Hedges et al. 1999):

$$
\text { Competition intensity }=\ln \frac{\text { Biomass }_{\text {mixture }}}{\text { Biomass }_{\text {alone }}}
$$

Where Biomass mixture is the biomass of the target species (S. grandis or S. krylovii) grown in mixture with a neighbor under the low (or high) soil nutrition treatment, andBiomass alone is the average biomass of the target species (S. grandis or S. krylovii) grown alone under the same soil nutrition treatment. The competition intensity is the degree to which competition contributes to the overall decrease in growth potential of an organism below its alone condition. Values of $\operatorname{lnRR}$ are symmetric around 0 , so that a positive value indicates a positive effect (competition facilitation) of the treatment on the target species and a negative value indicates a negative effect (competition inhibition).

In addition, to quantify the importance of competition, we calculated the neighbor-effect importance with additive symmetry $\left(N I m p_{A}\right)$ as recommended by Díaz-Sierra et al. (2016):

$$
\mathrm{NImp}_{A}=2 \frac{\text { Biomass }}{2 \text { MaxBiomass alone }- \text { Biomass alone }+\mid \text { Biomass } \mid}
$$

Where Biomass is calculated asBiomass mixture - Biomass alone, indicating the total impact of neighbors, and it is positive for facilitation and negative for inhibition. $\mid$ Biomass $\mid$ is its absolute value, and MaxBiomass alone is the maximum of the biomass grown alone under both soil nutrition conditions. The importance of competition is the relative contribution of the presence of a neighbor among all processes (i.e. soil nutrition) that affect the organism's performances and population dynamics.

For each target species, we got its intensity and importance of competition within each soil nutrition condition (2) and neighbor (3) cross-treatment, respectively.

\section{Nutrition-addition measurements}

Similar to the index of competition intensity, we quantified the nutrition-addition effect with LnRR:

$$
\text { Nutrition }- \text { addition ef fect }=\ln \frac{\text { Biomass }_{h \text { igh nutrition }}}{\text { Biomass }_{\text {low nutrition }}}
$$

Where Biomass high nutrition is the biomass of the target species (S. grandis or S. krylovii) grown under high nutrition treatment, and Biomass low nutrition is the average biomass of the target species (S. grandis or $S$. krylovii ) grown under low nutrition treatment. The nutrition-addition effect was calculated within each target species (2) and plantation condition (4) cross-treatment, respectively.

\section{Statistical analyses}


All data met the assumption of normality and homogeneity of variance, and were analyzed by using SPSS 21.0 (IBM, Chicago, IL, USA).

General linear model - univariate analysis was performed to assess the effect of target species, soil nutrition condition, and plantation condition on the biomass and root: shoot ratio, with all factors as fixed factors. In addition, Duncan's post hoc analysis was conducted to evaluate the differences of the mean value among these treatments.

General linear model - univariate analysis was used to estimate how target species, soil nutrition condition, and neighbor species influenced the intensity and importance of competition, with these factors as fixed factors. Moreover, the magnitude of effects $\left(\omega^{2}\right)$ of individual factor or the interaction of two or three factors were calculated by dividing each variance component to the total response variable (Graham et al. 2001). In addition, the directionality of the $N \operatorname{Imp}_{A}$ was assessed using one-sample $t$ test, where a value $>0$ indicates a significant facilitation effect of the neighbor on the target species, suggesting the trend of co-existence. While a value $<0$ indicates a significant inhibition effect, suggesting the trend of competitive exclusion. Furthermore, we estimated the difference of $N \operatorname{Imp}_{A}$ on the same target species between high and low nutrition treatments by independent sample $t$ test.

In order to analyze the change of competitive hierarchy, the effects of target species, soil nutrition and their interaction on the competition intensity were analyzed for each neighbor species by general linear model univariate analysis, with target species and soil N condition as fixed factors; and Duncan's post hoc analysis was conducted to evaluate the differences of the mean value among these four treatments. The significant interaction between target species and soil nutrition condition would suggest the competition change between S. grandisand S. krylovii .

The effect of target species, plantation condition on the nutrition-addition effect was estimated by general linear model - univariate analysis, with target species and plantation condition as fixed factors. When significant interaction effect of target species and plantation condition was found, a simple-effect analysis was used to evaluate the differences among levels of one factor under a certain condition of another factor. Moreover, the difference of the nutrition-addition with zero was assessed using one-sample $t$ test.

\section{Results}

\section{Biomass and root: shoot ratio}

The biomass was significantly $(P<0.05)$ influenced by the target species $(\mathrm{T})$, soil nutrition condition $(\mathrm{SNu})$, plantation condition $(\mathrm{Pc})$ and their interaction (Table 1). The biomass of $S$. krylovii grown in mixture with $S$. grandis under high nutrition treatment showed the highest value (Fig. 1).

Only the factor of Pc significantly $(P<0.05)$ influenced the root: shoot ratio. The root: shoot ratio was lower inS. grandis - S. krylovii mixture system than that grown alone or in mixture with L. chinensis, and the value in mixture with $A$. cristatum showed no difference with that in any of the other three systems (Fig. 1).

\section{Intensity and importance of competition}

All factors significantly $(P<0.05)$ influenced the intensity of competition except the factor of soil nutrition condition $(\mathrm{SNu})$, and all factors significantly influenced the importance of competition except the interaction of target species and soil nutrition condition $(\mathrm{T} \times \mathrm{SNu})$. Magnitude of effects $\left(\omega^{2}\right)$ of all factors explained about $62 \%$ and $68 \%$ of the total variance in the intensity and importance of competition, respectively; and the factor of neighbor species contributed the most portion to the total variance, with $29.448 \%$ for intensity of competition and $31.591 \%$ for importance of competition (Table 2).

The competition intensity was not significantly influenced by the interaction of $\mathrm{T} \times \mathrm{SNu}$ in mixture with L. chinensis and inS. grandis - S. krylovii mixture system. The competition inhibition enhanced in mixture with $L$. chinensis while it reduced in $S$. grandis - S. krylovii mixture system with the increase of soil nutrition, respectively (Fig. 2a, 2c). In mixture with A. cristatum, the competition intensity was significantly 
influenced by the interaction of $\mathrm{T} \times \mathrm{SNu}$, with the reduction of competition inhibition on S. grandis and the enhancement of competition inhibition on $S$. krylovii with the increase of soil nutrition (Fig. 2b).

The results of one sample $t$ test showed that five out of $12 N I m p_{A}$ were significantly $(P<0.01)$ negative; and the other seven $N \operatorname{Imp}_{A}$ were not different with zero. The significantly negative $N \operatorname{Imp}_{A}$ on $S$. grandis was shown in mixture with $L$. chinensis under both soil nutrition treatments and in mixture with $A$. cristatum under low nutrition treatment. The significantly negative $N \operatorname{Imp}_{A}$ on $S$. krylovii was shown in mixture with L. chinensis or A. cristatum under high nutrition treatment (Fig. 3). In addition, the NImp $p_{A}$ on S. grandis in mixture with $L$. chinensis, and that on $S$. krylovii in mixture with L. chinensis or A. cristatum were more negative under the high nutrition treatment than those under the low nutrition treatment, respectively.

\section{Nutrition-addition effect}

The values of nutrition-addition effect were higher than zero except the one on $S$. grandis in mixture with L. chinensis. The nutrition-addition effect was significantly influenced by the effects of target species, plantation condition and their interaction. Regarding $S$. grandis, the nutrition-addition effect was lower in mixture with $L$. chinensis than grown in any of the other plantation conditions. As for S. krylovii, the nutrition-addition effect was relatively lower in mixture with $L$. chinensis or A. cristatum than in any of the other two conditions. Compared with the mean value of $S$. grandis in the same plantation conditions, the nutrition-addition effect of $S$. krylovii was relatively lower in mixture with $A$. cristatum but was relatively higher in any of the other three plantation conditions (Fig. 4).

\section{Discussion}

The present results showed the complexity of the competitors (targets and neighbors) in influencing the outcomes of plant-plant interaction and supported that the biotic factors played an important role in influencing intrinsic mechanism of plant-plant interaction. Firstly, the effects of neighbor species were significant on the intensity and importance of competition, and the $\omega^{2}$ value of neighbor species was the highest among all predictors, which explained $29.448 \%$ and $31.591 \%$ of the total variance in the intensity and importance of competition, respectively (Table 2). Recently, more and more studies indicated the different neighbors could show different effects on the nutrition availability by direct resource depletion or changes of the soil microbial composition and activities as the indirect (Schofield et al. 2018; Suding et al. 2004; Zhang et al. 2019). Similarly, the competition intensity of different target species neighbored by the same neighbor was different from each other (Pérez-Ramos et al. 2019; Saccone et al. 2017). Secondly, only the factor of plantation condition (grown alone or in mixtures with different neighbors) significantly influenced the root: shoot ratio, which indicated that different neighbors resulted in different nutrition availability for target species or influenced the nutrition absorption of the target species, independently of the soil nutrition conditions (Uddin et al. 2020; Zhang et al. 2008). Therefore, in the present study, we found several mechanisms potentially contribute to these differential neighbor effects on different target species, as mentioned by other researchers (Bertness and Callaway 1994; Grime, 1977; Grime, 1979; Suding and Goldberg 2001).

First, when $S$. grandis or $S$. krylovii was grown in mixture with $L$. chinensis, the intensity and importance of competition inhibition increased with the addition of soil nutrition, supporting "stress gradient hypothesis" and Grime's theory (Bertness and Callawa 1994; Grime, 1977). In addition, the importance of competition was significantly negative on $S$. grandis under both soil nutrition treatments and on S. krylovii under high soil nutrition treatment, which suggested that the competition effects of the neighbor played an important role in affecting the performances of target species (Díaz-Sierra et al. 2016). In addition, the importance of competition was not significant on S. krylovii under the low soil nutrition treatment, suggesting that the ability of species to tolerate low resource availability could influence the importance of competition, like the results found in other researches (Delerue et al. 2018; Gaucherand et al. 2006). What is more, in mixture with $L$. chinensis, the relatively higher root: shoot ratio indicated that resource competition is main dominant driver, and the nutrition-addition effect was lowest for each target species among all plantation conditions and was non-significant on S. grandis (Fig. 4). That is to say, L. chinensis could inhibit the 
resource availability and increase the competitive inhibition on its competitors, which was consistent with the finding in the PSF experiment (Zhao et al. 2018). All these results demonstrated that as a dominant species, L. chinensis could impact resources to benefit itself or to inhibit other species. Similar performance that a plant species captures a large percentage of limiting resource in a given area and reduces that resource for other species growing nearby have been reported in many researches (Groves et al. 2003; Parker et al. 2019).

Second, when S. grandis and S. krylovii were grown together, the competition inhibition decreased with the increasing soil nutrition but it was influenced by the interaction between target species and soil nutrition condition (Fig. 2), supporting the theory of competitive reduction. In this case, high nutrition treatment could modify species associations simply but not change the community composition (Suding and Goldberg 2001). A research has indicated that light competition was the main driver in the stable or restoration community of $S$. grandis where community height and canopy density were high enough (Li et al. 2017). The lowest value of root: shoot ratio was found in S. grandis - S. krylovii mixture system (Fig. 1B), which indicated that the resource allocation model was in favor of aerial competition such as light and space according to the balanced growth hypothesis (Davidson, 1969). However, in this study, the resource of light or space was not limited because only two seedlings were grown in one microcosm. All these facts confirmed the results that the importance of competition was not significant on each target species in $S$. grandis - $S$. krylovii mixture system. That is to say, the relative contribution of competition among all processes could be ignored in affecting the individuals' performances and population dynamics of $S$. grandis and S. krylovii (Diaz-Sierra et al. 2016).

The biomass of $S$. krylovii was higher than that of $S$. krylovii under the high nutrition treatment when each species was grown alone, indicated that the growth potential of $S$. krylovii was comparable to or even greater than that of $S$. grandis. This could explain the reason that $S$. krylovii appears in the disturbance region of $S$. grandis communities, supporting that the gap of light niches is very important for S. krylovii and proving that recognizing the nature of competition mechanisms (here is competition reduction) is very important for ecologists to understand and explain the community dynamics (Suding, 2001). Such results also suggested that $S$. krylovii was an inferior competitor for light or space but not for nutrition in the stable $S$. grandis communities and resulted in competition exclusion gradually in the closed canopy communities because the individuals of $S$. krylovii were suppressed and shaded by taller canopy species such as $S$. grandis - In addition, the biomass of $S$. krylovii was highest under the high nutrition treatment in $S$. grandis S. krylovii mixture system (Fig. 1a), which supported that the presence of $S$. grandis could facilitate the growth of S. krylovii and enhance the nutrition-addition effect of $S$. krylovii (Zhao et al. 2018).

Third, when each target species was grown in mixture with A. cristatum, the competition inhibition on $S$. grandis decreased and that on $S$. krylovii increased, and the relative competitive hierarchies of $S$. grandis and S. krylovii changed with the change of soil nutrition condition, which supported the theory of competitive change (Suding and Goldberg 2001). In this case, the change of soil nutrition condition could not only modify species associations but also change the community composition (Suding and Goldberg 2001). Such speciesspecific responses and shifts in competitive priority along environmental gradients caused by the significant differences among species in their growth potentials and their tolerance under a particular condition (Hartley et al. 2005). For example, Suding et al. (2004) showed that the inhibitory effects associated withAcomastylis rossii were offset to a greater degree than those associated with Deschampsia caespitosa when N supply rates were enhanced through repeated $\mathrm{N}$ additions. Our findings indicated that the intensity and importance of competition inhibition of A. cristatum on $S$. krylovii increased significantly with the increase of soil nutrition might be caused by the significantly lower nutrition-addition effect on $S$. krylovii in mixture with A. cristatum than in any of the other plantation conditions or than that on S. grandis (Fig.4). In a plant-soil feedback experiment,S. krylovii grown in the soil conditioned by $A$. cristatumshowed the lower N-addition effect than that in the soil conditioned by $S$. grandis (Zhao et al. 2018). Thus, both the legacy effects and the immediate effects of plant species could strongly influence plants' performance and nutrition availability by a similar pattern, suggesting that the outcomes of plant-plant interaction might be mediated by soil microbial community or by the combination of resource depletion and soil microbial community (Larios et al. 2015). 
Our findings supported that the intensity and importance of competition and their variations along soil nutrition conditions were species dependent and proved that plant-plant interactions can have significant ecological and evolutionary influences on the niches of species (Strauss, 2014). Although some studies have indicated that the abiotic soil condition but not neighbors played more important roles in influencing the competitive hierarchy (Suding, 2001), more and more studies including ours supported the significant effects of neighbors and the interaction between abiotic soil condition and neighbor species on the competitive hierarchy (Fynn et al. 2005; Van den Berge et al. 2014). In this study, we also confirmed that the growth potential of $S$. krylovii is not lower than that of $S$. grandis, thus, higher tolerance to unfertile condition and lower tolerance to reduced canopy openness (light) of $S$. krylovii determined its distribution. The resource conditions of light or space and soil nutrient could be influenced by biotic factors such as neighbors or abiotic factors such as disturbance or $\mathrm{N}$ deposition, which makes all possible two-species equilibria unstable in the face of the global changes.

\section{Data Accessibility}

The original data used in the experiment is stored in in a publicly accessible repository Dryad deposit:https://doi.org/10.5061/dryad.7wm37pvq8

\section{Conflict of interest}

None declared

\section{Author Contribution}

Nianxi Zhao: Conceptualization (Lead);Data curation (Lead);Funding acquisition (Equal); Resources (Equal); Software (Lead); Visualization (Lead); Writing-original draft (Lead); Yujuan Xu:Conceptualization (Supporting); Project administration (Supporting); Visualization (Supporting); Writing-original draft (Supporting); Writing-review \& editing (Supporting); Liping Chen:Investigation (Lead); Methodology (Lead); Man Jiang:Visualization (Supporting); Writing-review \& editing (Supporting);Ke Dong: Conceptualization (Supporting); Investigation (Supporting); Jinlong Wang: Project administration (Equal); Resources (Equal); Writing-review \& editing (Equal); Yubao Gao: Project administration (Equal); Resources (Equal).

\section{Acknowledgements}

This work was supported by the National Key Research and Development Program of China (No. 2017YFD0200808) and National Natural Science Foundation of China (31770505).

\section{References}

Bertness MD, Callaway R (1994). Positive interactions in communities. Trends in Ecology 85 Evolution 9 :191-193.

Brooker R, Kikvidze Z, Pugnaire FI, Callaway RM, Choler P, Lortie CJ, Michalet R (2005). The importance of importance. Oikos 109 :63-70.

Brooker RW, Maestre FT, Callaway RM, Lortie CL, Cavieres LA, Kunstler G, Liancourt P, Tielborger K, Travis JMJ, Anthelme F (2008). Facilitation in plant communities: The past, the present, and the future. Journal of Ecology 96 :18-34.

Chen D, Xing W, Lan Z, Saleem M, Wu Y, Hu S, Bai Y (2019). Direct and indirect effects of nitrogen enrichment on soil organisms and carbon and nitrogen mineralization in a semi-arid grassland. Functional Ecology $33: 175-187$.

Chen LP, Zhao NX, Zhang LH, Gao YB (2013). Responses of two dominant plant species to drought stress and defoliation in the inner mongolia steppe of China. Plant Ecology214:221-229.

Diaz-Sierra R, Verwijmeren M, Rietkerk M, Resco de Dios V, Baudena M (2016). A new family of standardized and symmetric indices for measuring the intensity and importance of plant neighbour effects. Methods 
in Ecology and Evolution :1-12.

Davidson RL (1969). Effect of root/leaf temperature differentials on root/shoot ratios in some pasture grasses and clover. Annals of Botany 33 :561-569.

Delerue F, Gonzalez M, Achat DL, Puzos L, Augusto L (2018). Competition along productivity gradients: News from heathlands. Oecologia $187: 219-231$.

Fynn RWS, Morris CD, Kirkman KP (2005). Plant strategies and trait trade-offs influence trends in competitive ability along gradients of soil fertility and disturbance. Journal of Ecology 93 :384-394.

Gaucherand S, Liancourt P, Lavorel S (2006). Importance and intensity of competition along a fertility gradient and across species. Journal of Vegetation Science $17: 455-464$.

Goldberg DE (1996). Competitive ability: Definitions, contingency and correlated traits.Philosophical Transactions of the Royal Society of London. Series B: Biological Sciences 351 :1377-1385.

Graham MH, Edwards MS (2001). Statistical significance versus fit: Estimating the importance of individual factors in ecological analysis of variance. Oikos 93 :505-513.

Grime JP (1977). Evidence for the existence of three primary strategies in plants and its relevance to ecological and evolutionary theory. The American Naturalist111 :1169-1194.

Grime JP (1979). Plant strategies and vegetation processes, John Wiley and Sons, Chichester, UK.

Groves RH, Austin MP, Kaye PE (2003). Competition between australian and introduced grasses along a nutrient gradient. Austral Ecology $28: 491-498$.

Hartley SE, Mitchell RJ (2005). Manipulation of nutrients and grazing levels on heather moorland: Changes in calluna dominance and consequences for community composition. Journal of Ecology 93 :990-1004.

Hedges LV, Gurevitch J, Curtis PS (1999). The meta-analysis of response ratios in experimental ecology. Ecology $80: 1150-1156$.

Huang M, Chai L, Jiang D, Zhang M, Zhao Y, Huang Y (2019). Increasing aridity affects soil archaeal communities by mediating soil niches in semi-arid regions. Science of the Total Environment 647:699-707.

Keddy P, Nielsen K, Weiher E, Lawson R (2002). Relative competitive performance of 63 species of terrestrial herbaceous plants. Journal of Vegetation Science13 :5-16.

Kong C-H, Zhang S-Z, Li Y-H, Xia Z-C, Yang X-F, Meiners SJ, Wang P (2018). Plant neighbor detection and allelochemical response are driven by root-secreted signaling chemicals.Nature Communications 9 :1-9.

Larios L, Suding KN (2015). Competition and soil resource environment alter plant-soil feedbacks for native and exotic grasses. AoB Plants 7 :plu077.

Laurent L, Marell A, Korboulewsky N, Said S, Balandier P (2017). How does disturbance affect the intensity and importance of plant competition along resource gradients? Forest Ecology and Management 391 :239-245.

Li J, Zheng Z, Xie H, Zhao N, Gao Y (2017). Increased soil nutrition and decreased light intensity drive species loss after eight years grassland enclosures. Scientific Reports $7: 44525$.

Li S, Verburg PH, Lv S, Wu J, Li X (2012). Spatial analysis of the driving factors of grassland degradation under conditions of climate change and intensive use in inner mongolia, China. Regional Environmental Change 12 :461-474.

Lu SL, Wu ZL (1996). On geographical distribution of the genus stipa 1. In China. Acta Phytotaxonomica Sinica $34: 242-253$.

Perez-Ramos IM, Matias L, Gomez-Aparicio L, Godoy O (2019). Functional traits and phenotypic plasticity modulate species coexistence across contrasting climatic conditions. Nature Communications 10 :1-11. 
Parker SS, Harpole WS, Seabloom EW (2019). Plant species natural abundances are determined by their growth and modification of soil resources in monoculture. Plant EJ Soil445 :273-287.

Read QD (2016). Individual variation in plant traits drives species interactions, ecosystem functioning, and responses to global change. Ph.D Dissertation, University of Tennessee - Knoxville.

Ren H, Eviner VT, Gui W, Wilson GW, Cobb AB, Yang G, Zhang Y, Hu S, Bai Y (2018). Livestock grazing regulates ecosystem multifunctionality in semi-arid grassland.Functional Ecology 32 :2790-2800.

Reynolds HL, Pacala SW (1993). An analytical treatment of root-to-shoot ratio and plant competition for soil nutrient and light. The American Naturalist141:51-70.

Robinson D, Davidson H, Trinder C, Brooker R (2010). Root-shoot growth responses during interspecific competition quantified using allometric modelling. Annals of Botany 106 :921-926.

Saccone P, Hoikka K, Virtanen R (2017). What if plant functional types conceal species-specific responses to environment? Study on arctic shrub communities.Ecology 98 :1600-1612.

Schofield EJ, Rowntree JK, Paterson E, Brooker RW (2018). Temporal dynamism of resource capture: A missing factor in ecology? Trends in Ecology $\&$ Evolution 33 :277-286.

Stoll P, Weiner J (2000). A neighborhood view of interactions among individual plants. In: The Geometry of Ecological Interactions: Simplifying Spatial Complexity, eds. Dieckmann U, Law R \& Metz JAJ, pp. 11-27. Cambridge University Press.

Strauss SY (2014). Ecological and evolutionary responses in complex communities: Implications for invasions and eco-evolutionary feedbacks. Oikos $123: 257-266$.

Suding KN (2001). The effects of gap creation on competitive interactions: Separating changes in overall intensity from relative rankings? Oikos $94: 219-227$.

Suding KN, Goldberg D (2001). Do disturbances alter competitive hierarchies? Mechanisms of change following gap creation. Ecology $82: 2133-2149$.

Suding KN, Larson JR, Thorsos E, Steltzer H, Bowman WD (2004). Species effects on resource supply rates: Do they influence competitive interactions? Plant Ecology 175 :47-58.

Tilman D (1982). Resource competition and community structure: Princeton University Press, Princeton, New Jersey, USA.

Tilman D (1987). On the meaning of competition and the mechanisms of competitive superiority.Functional Ecology 1 :304-315.

Uddin MN, Robinson RW, Asaeda T (2020). Nitrogen immobilization may reduce invasibility of nutrient enriched plant community invaded by phragmites australis.Scientific Reports 10 :1601 https://doi.org/10.1038/s41598-020-58523-4

Van den Berge J, Naudts K, De Boeck H, Ceulemans R, Nijs I (2014). Do interactions with neighbours modify the above-ground productivity response to drought? A test with two grassland species. Environmental and Experimental Botany 105 :18-24.

Xu B, Ren HQ, Zhao NX, Ruan WB, Gao YB (2015). Community analysis of soil nematodes associated with four grassland species in the inner mongolian steppe. Chinese Journal of Ecology 34:175-181.

Yelenik SG, D'Antonio CM, August-Schmidt E (2017). The influence of soil resources and plant traits on invasion and restoration in a subtropical woodland.Plant Ecology 218 :1149-1161.

Zhang D, Lyu Y, Li H, Tang X, Hu R, Rengel Z, Zhang F, Whalley WR, Davies WJ, Cahill Jr JF (2019). Neighbouring plants modify maize root foraging for phosphorus: Coupling nutrients and neighbours for improved nutrient-use efficiency. New Phytologist :1-10. 
Zhang J, Cheng G, Yu F, Krauchi N, Li MH (2008). Intensity and importance of competition for a grass (Festuca rubra) and a legume (Trifolium pratense) vary with environmental changes. Journal of Integrative Plant Biology 50 :1570-1579.

Zhao N, Gao S, Ren H, Yang X, Sun Z, Wang J, Jiang L, Gao Y (2018). Competition alters plant-soil feedbacks of two species in the inner mongolia steppe, China. Plant \& Soil429 :425-436.

Zhou L, Shen H, Chen L, Li H, Zhang P, Zhao X, Liu T, Liu S, Xing A, Hu H (2019). Ecological consequences of shrub encroachment in the grasslands of northern China. Landscape Ecology 34 :119-130.

Zhu TC (2004). Ccological and biological characteristics of Leymus chinensis, Changchun: Jilin Science and Eechnology Press.

Table 1: Results of general linear model for the biomass and root: shoot ratio

\begin{tabular}{llllllll}
\hline Source & df & Biomass & Biomass & Biomass & Root: shoot ratio & Root: shoot ratio & Root: \\
\hline & & Sum of squares & $F$ & $P$-value & Sum of squares & $F$ & \\
Target species $(\mathrm{T})$ & 1 & 0.251 & 20.726 & $<0.001$ & 0.08 & 1.27 & 0.263 \\
Soil nutrition condition $(\mathrm{SNu})$ & 1 & 0.961 & 79.311 & $<0.001$ & 0.06 & 1.01 & 0.317 \\
Plantation condition $(\mathrm{Pc})$ & 3 & 0.212 & 17.503 & $<0.001$ & 0.59 & 3.28 & 0.025 \\
$\mathrm{~T} \times \mathrm{SNu}$ & 1 & 0.195 & 16.126 & $<0.001$ & 0.36 & 2.00 & 0.121 \\
$\mathrm{~T} \times \mathrm{Pc}$ & 3 & 0.047 & 3.883 & 0.012 & 0.00 & 0.02 & 0.901 \\
$\mathrm{SNu} \times \mathrm{Pc}$ & 3 & 0.117 & 9.664 & $<0.001$ & 0.34 & 0.88 & 0.533 \\
$\mathrm{~T} \times \mathrm{SNu} \times \mathrm{Pc}$ & 3 & 0.055 & 4.536 & 0.005 & 0.13 & & \\
Error & 80 & 0.969 & & & 4.822 & & \\
\hline
\end{tabular}

Table 2: Results of general linear model for the intensity and importance and the magnitude of effects $\left(\omega^{2}\right)$ explained by each unique factor

\begin{tabular}{lllll}
\hline Source & df & Intensity of competition, LnRR & Intensity of competition, LnRR & Intensity of comp \\
\hline & & $F$ & $P$-value & Magnitude of effe \\
Target species (T) & 1 & 14.49 & $<0.001$ & 9.180 \\
Soil nutrition condition $(\mathrm{SNu})$ & 1 & 3.68 & 0.06 & 2.329 \\
Neighbor species (Nr) & 2 & 23.24 & $<0.001$ & 29.448 \\
$\mathrm{~T} \times \mathrm{SNu}$ & 1 & 6.38 & 0.014 & 4.042 \\
$\mathrm{~T} \times \mathrm{Nr}$ & 2 & 3.63 & 0.033 & 4.595 \\
$\mathrm{SNu} \times \mathrm{Nr}$ & 2 & 9.85 & $<0.001$ & 12.480 \\
$\mathrm{~T} \times \mathrm{SNu} \times \mathrm{Nr}$ & 2 & 3.97 & 0.024 & 5.037 \\
Error & 60 & & 38.022 \\
\hline
\end{tabular}

\section{Figure legends}

Fig. 1: Total biomasses (a) and root: shoot ratio (b) ofStipa grandis and S. krylovii under different conditions. Non-significant difference is shown by the same English letter.

Fig. 2: Results of analysis of variance on competitive intensity on S. grandis and S. krylovii both under the high and low nutrition treatments in each plantation condition. (a) in mixture with L. chinensis , (b) in mixture with A. cristatum and (c) in S. grandis - S. krylovii mixture system. Non-significant difference among the average values of the competition intensity in the same box is indicated by the same English letter.

Fig. 3: The importance of competition $\left(N I m p_{A}\right)$ on S. grandis and S. krylovii under different conditions. 
Significant differences with 0 are indicated by asterisks $\left({ }^{* *} P<0.01 ;{ }^{* * *} \mathrm{P}<0.001\right)$ and non-significant differences are indicated by 'ns'. The significantly negative $N \operatorname{Imp}_{A}$ under the high nutrition treatment than that under the low nutrition treatment is shown by -.

Fig. 4: Effects of target species and plantation condition on the nutrition-addition effect. Significant differences between the average value of $S$. grandisand $S$. krylovii are indicated by asterisks $(* * P<0.01$; $\left.{ }^{* * *} P<0.001\right)$. Non-significant differences among plantation conditions for the same target species are indicated by the same English letters. All average values are significantly higher than zero except the one with 'ns'.

Fig. 1: Total biomasses (a) and root: shoot ratio (b) ofStipa grandis and S. krylovii under different conditions. Non-significant difference is shown by the same English letter.

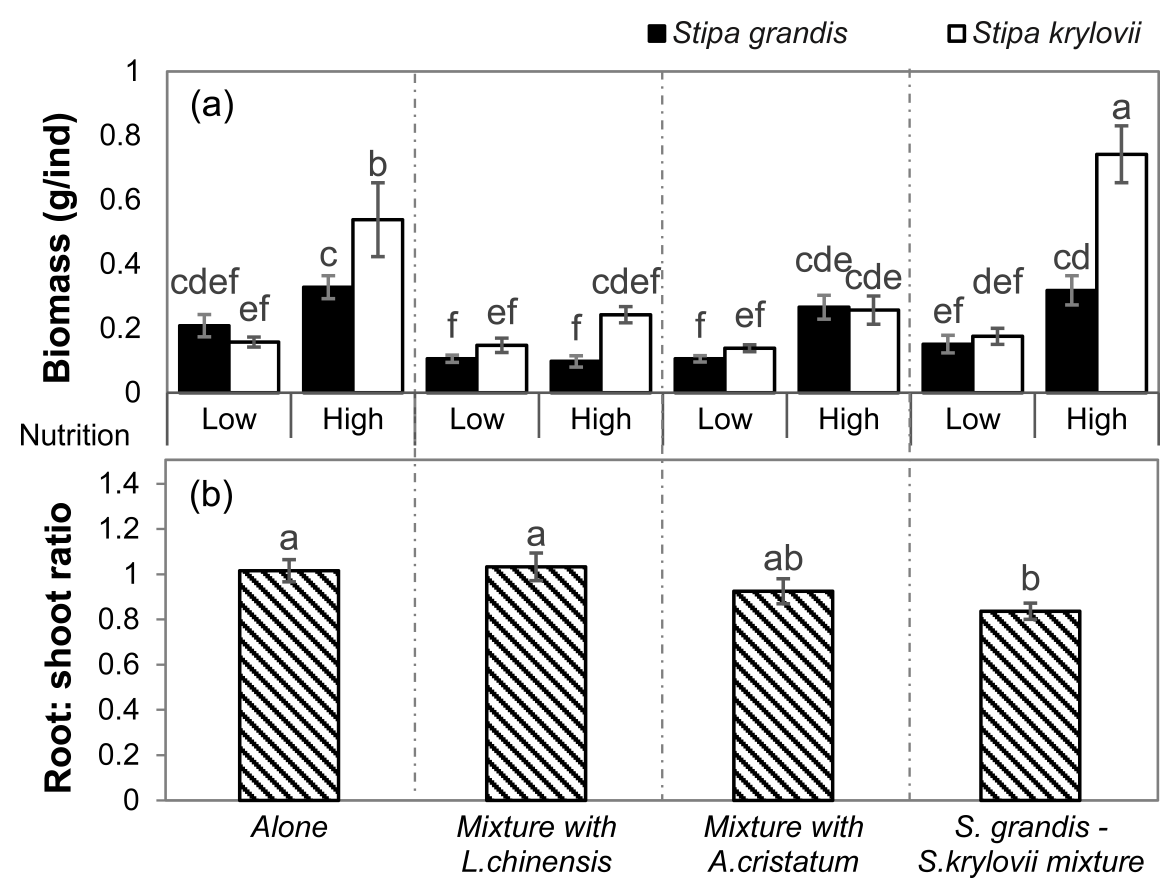

Fig. 2: Results of analysis of variance on competitive intensity on S. grandis and S. krylovii both under the high and low nutrition treatments in each plantation condition. (A) in mixture with L. chinensis , (B) in mixture with $A$. cristatum and (C) in S. grandis - S. krylovii mixture system. Non-significant difference among the average values of the competition intensity in the same box is indicated by the same English letter.

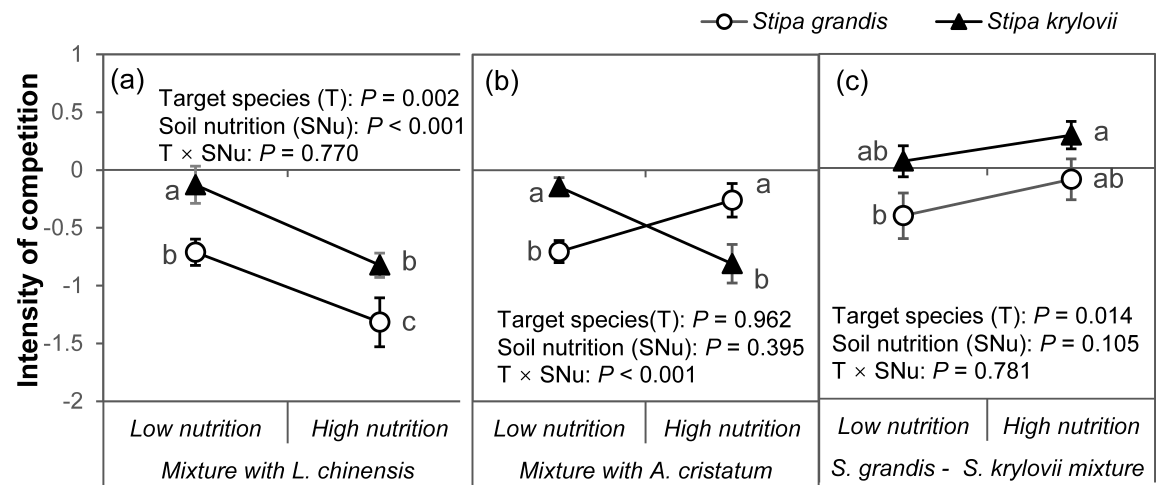


Fig. 3: The importance of competition $\left(N I m p_{A}\right)$ on S. grandis and S. krylovii under different conditions. Significant differences with 0 are indicated by asterisks $\left({ }^{* *} P<0.01 ;{ }^{* * *} \mathrm{P}<0.001\right)$ and non-significant differences are indicated by 'ns'. The significantly negative $N I m p_{A}$ under the high nutrition treatment than that under the low nutrition treatment is shown by -.

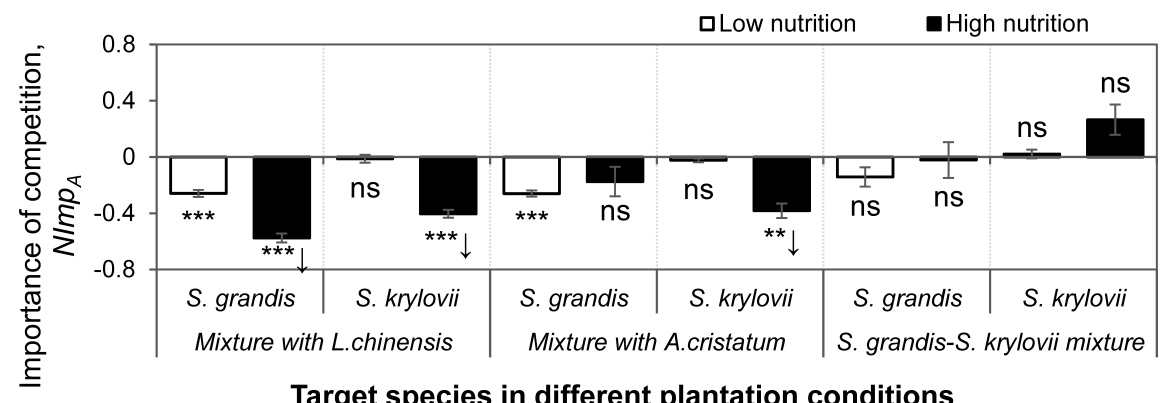

Target species in different plantation conditions

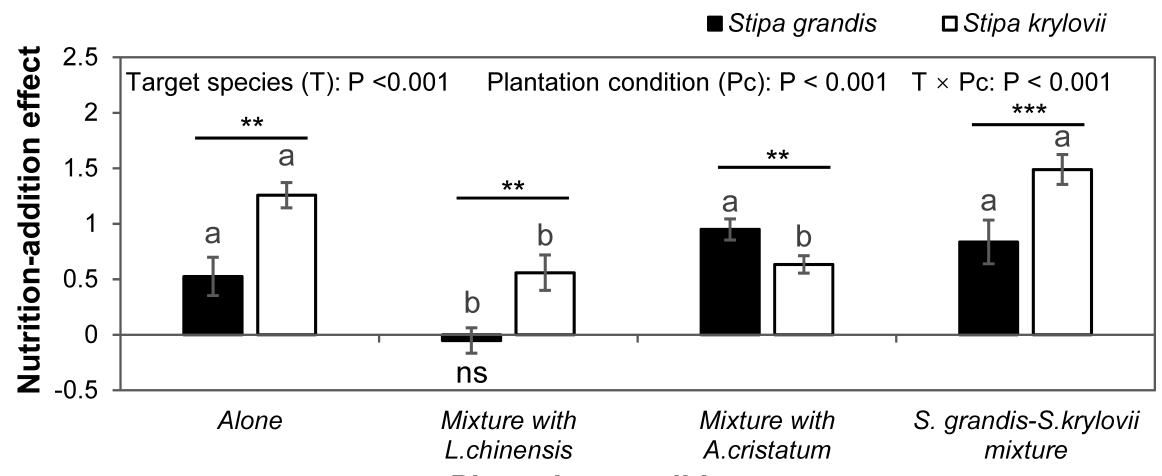

Plantation conditions

Fig. 4: Effects of target species and plantation condition on the nutrition-addition effect. Significant differences between the average value of $S$. grandis and $S$. krylovii are indicated by asterisks $(* * P<0.01$; $\left.{ }^{* * *} P<0.001\right)$. Non-significant differences among plantation conditions for the same target species are indicated by the same English letters. All average values are significantly higher than zero except the one with 'ns'.

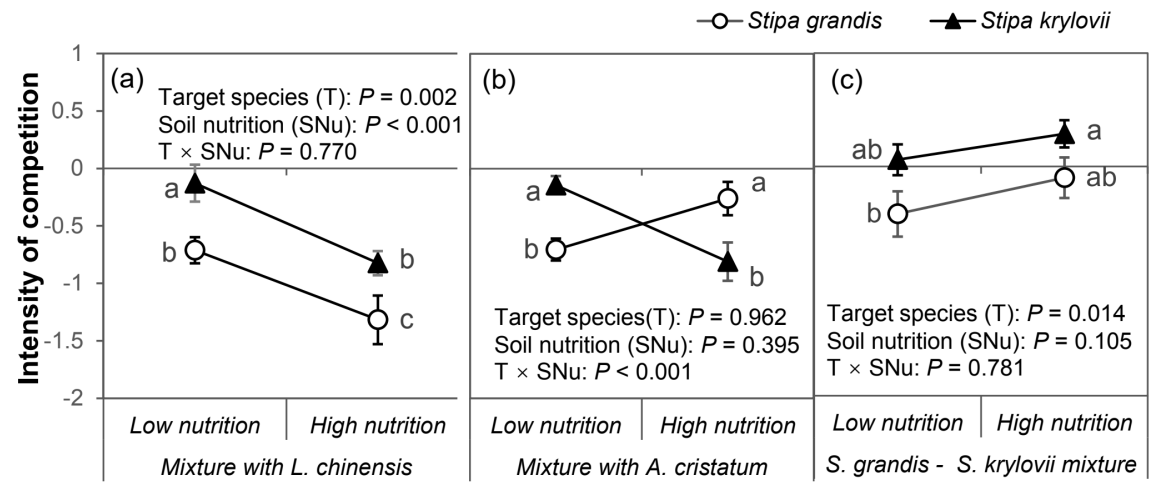



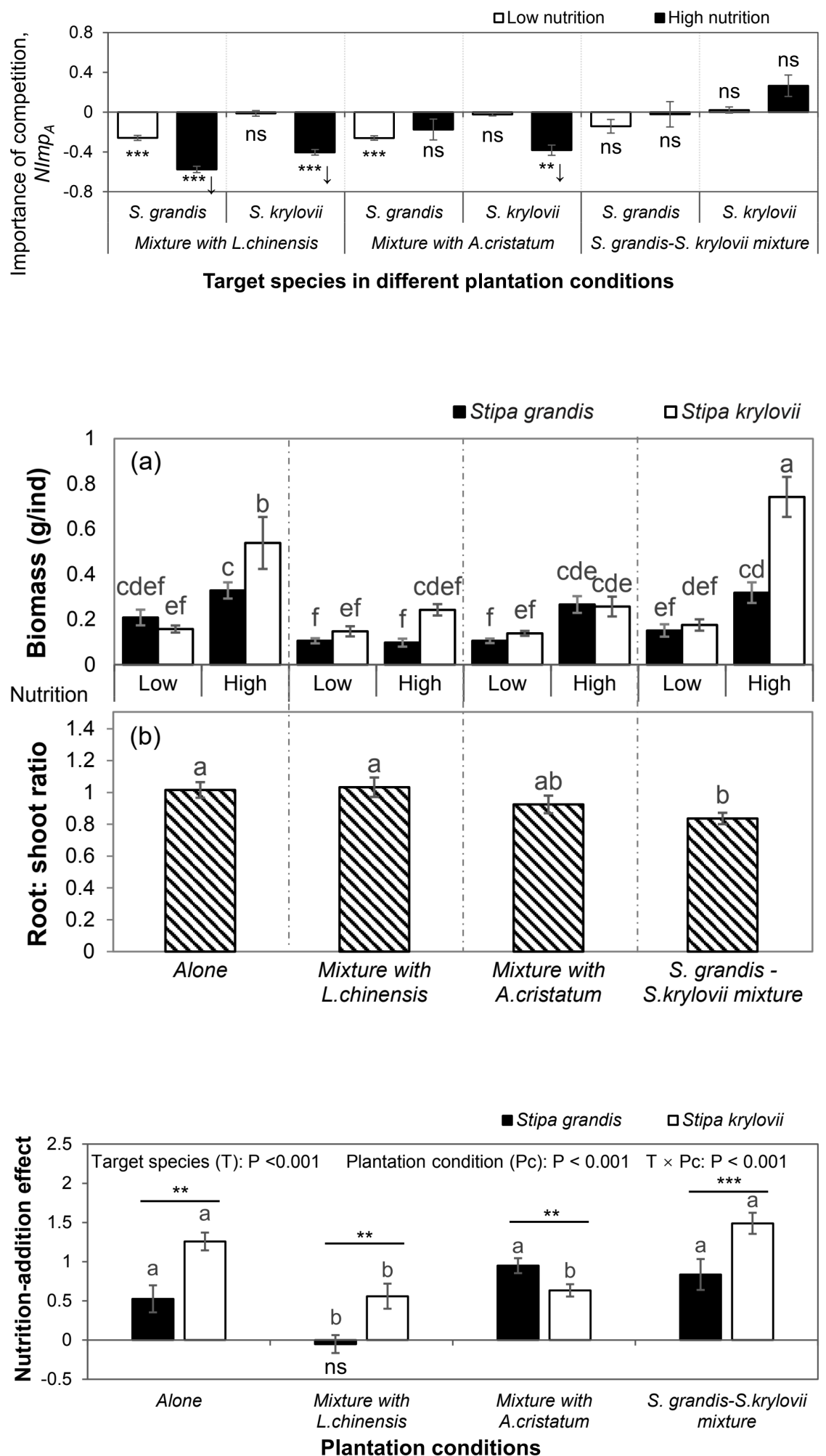